\title{
Velociraptorine dromaeosaurid teeth from the Kimmeridgian (Late Jurassic) of Germany
}

Torsten van der Lubbe, Ute Richter, and Nils Knötschke

Acta Palaeontologica Polonica 54 (3), 2009: 401-408 doi: http://dx.doi.org/10.4202/app.2008.0007

Six theropod teeth from a Late Jurassic (Kimmeridgian) bone bed in Langenberg Quarry of Oker (Goslar, Germany) are identified as a new dromaeosaurid taxon, here left in open nomenclature. Direct comparison reveals that the teeth are very similar to velociraptorine dromaeosaurid teeth from the Guimarota coal mine (Late Jurassic, Portugal) and to velociraptorine dromaeosaurid teeth from Uña (Barremian, Cuenca Province, Spain). Our data indicate that the teeth from the Kimmeridgian of Lower Saxony are of velociraptorine dromaeosaurid type, and therefore represent one of the oldest occurrences of the group Dromaeosauridae.

Key words: Saurischia, Theropoda, Dromaeosauridae, velociraptorine, teeth, Late Jurassic, Germany.

Torsten van der Lubbe [Torsten.v.d.Lubbe@web.de] and Ute Richter [ute.richter2@gmx.net ], Lower Saxony State Museum, Willy-Brandt-Allee 5, 30169 Hannover, Germany; Nils Knötschke [palaeo_nils@ hotmail.com], Dinosaurier-Freilichtmuseum Münchehagen, Alte Zollstrasse 5, 31547 Rehburg-Loccum, Germany.

This is an open-access article distributed under the terms of the Creative Commons Attribution License (for details please see creativecommons.org), which permits unrestricted use, distribution, and reproduction in any medium, provided the original author and source are credited. 